\title{
CRESCIMENTO E SOBREVIVÊNCIA DE ESPÉCIES ARBÓREAS EM SISTEMA AGROFLORESTAL EXPERIMENTAL EM SANTARÉM, PARÁ
}

\author{
Cleise Rebelo Pimentel'; Cezarina do Socorro de Souza Carvalho²; Daniela Pauletto; Lucas Sérgio de \\ Sousa Lopes ${ }^{4}$; Rafael Rode ${ }^{5}$ \\ ${ }^{1}$ Universidade Federal do Oeste do Pará, Santarém, Pará, Brasil, cleiserebelopimentel@gmail.com \\ 2 Universidade Federal do Oeste do Pará, Santarém, Pará, Brasil, cezarina13@gmail.com \\ ${ }^{3}$ Universidade Federal do Oeste do Pará, Santarém, Pará, Brasil, paulettoflorestal@gmail.com \\ ${ }^{4}$ Universidade Federal do Oeste do Pará, Santarém, Pará Brasil, lucaasergio@gmail.com \\ ${ }^{5}$ Universidade Federal do Oeste do Pará, Santarém, Pará, Brasil, rafaelrode@gmail.com
}

RESUMO: Este trabalho teve como objetivo avaliar o crescimento inicial e sobrevivência de três espécies florestais de importância econômica e ecológica implantadas em sistema agroflorestal sob diferentes condições de preparo de área e manejo. O experimento foi realizado na Fazenda Experimental da Universidade Federal do Oeste do Pará - UFOPA, no período de nove meses, com as espécies: Ipê Amarelo (Handroanthus serratifolius (Vahl) S.O. Grose), Paricá (Schizolobium parahyba var. amazonicum (Huber ex Ducke) Barneby) e Mogno Brasileiro (Swietenia macrophylla King). Foram mensuradas as variáveis altura total (Ht) e diâmetro a altura do colo (DAC) utilizando trenas e paquímetro digital. Calculou-se as Taxas de Crescimento Relativo (TCR) das espécies para os parâmetros Ht e DAC. As análises foram realizadas através do software Bioestat. As espécies apresentaram respostas satisfatórias, para crescimento inicial, em relação as variáveis observadas podendo ser indicadas para plantio sistemas agroflorestais.

PALAVRAS-CHAVE: Amazônia, Agrofloresta, Espécies florestais.

\section{GROWTH AND SURVIVAL OF TREE SPECIES IN AN EXPERIMENTAL AGROFORESTRY SYSTEM IN SANTARÉM, PARÁ}

ABSTRACT: This work aims to evaluate the initial growth and survival of three forest species of economic and ecological importance implanted in an agroforestry system under different conditions of area preparation and management. The experiment was carried out at the Experimental Farm of the Federal University of West of Pará (UFOPA), in the period of nine months, with the species: Ipê Amarelo (Handroanthus serratifolius (Vahl) SO Grose), Paricá (Schizolobium parahyba var. Amazonicum (Huber ex Ducke) Barneby) and Brazilian Mahogany (Swietenia macrophylla King). The variables total height $(\mathrm{Ht})$ and diameter at the height of the neck (DON) were measured using a digital caliper and pachymeter. Relative Growth Rates (TCR) of the species were calculated for the Ht and DAC parameters. The analyzes were performed 
using Bioestat software. The species presented satisfactory responses, for initial growth, in relation to the observed variables and agroforestry systems could be indicated for planting.

KEYWORDS: Amazon, Agroforestry, Forest species.

\section{CRECIMIENTO Y SUPERVIVENCIA EN ESPECIES ARBÓREAS EN SISTEMA AGROFLORESTAL EXPERIMENTAL EN SANTARÉM, PARÁ}

RESUMEN: Este trabajo tuvo como objetivo evaluar el crecimiento inicial y supervivencia de tres especies forestales de importancia económica y ecológica implantadas en sistema agroforestal bajo diferentes condiciones de preparación de área y manejo. El experimento fue realizado en la Hacienda Experimental de la Universidad Federal del Oeste de Pará - UFOPA, en el período de nueve meses con las especies: Ipê Amarelo (Handroanthus serratifolius (Vahl) SO Grose), Paricá ( Schizolobium parahyba var. amazonicum (Huber ex Ducke) Barneby) y Mogno Brasileiro (Swietenia macrophylla King). Se midieron las variables altura total $(\mathrm{Ht})$ y el diámetro a la altura del cuello (DAC) utilizando trenas y paquímetro digital, respectivamente. Se calcularon las tasas de crecimiento relativo (TCR) de las especies para los parámetros Ht y DAC. Los análisis se realizaron a través del software Biostat. Las especies presentaron respuestas satisfactorias en relación a las variables observadas. Pueden ser indicadas para plantío sistemas agroforestales

PALABRAS CLAVE: Amazonia, Agrofloresta, Especies forestales.

Os Sistemas Agroflorestais (SAFs) constituem sistemas de uso e ocupação do solo em que plantas lenhosas perenes (árvores, arbustos, palmeiras) são manejadas em associação com plantas herbáceas, culturas agrícolas e/ou forrageiras e/ou em integração com animais, em uma mesma unidade de manejo, de acordo com um arranjo espacial e temporal, com alta diversidade de espécies e interações ecológicas entre estes componentes (ABDO, 2008; MARTINOTTO et al., 2012).

Tais sistemas podem contribuir para a melhoria da região, através da manutenção da biodiversidade, melhorando as condições do solo, bem 
como seus atributos químicos, físicos e biológicos reduzindo a erosão, além de mudanças sociais e econômicas e o fornecimento de vários produtos e serviços ambientais (RODRIGUES et al., 2008; LIMA et al., 2010). Por tais motivos, essa modalidade de cultivo vem sendo apontada principalmente para regiões tropicais, como alternativa para elevar a sustentabilidade dos agroecossistemas e renda de pequenos e médios produtores (VALERI et al., 2003).

O sistema de plantações mistas compostas de árvores nativas parece ser o mais adequado para atender aos objetivos propostos, por manterem, embora parcialmente, os processos que caracterizam a eficiência de conservação ambiental dos sistemas florestais naturais (MELOTTO et. al., 2009).

Dentro desse contexto, as espécies florestais arbóreas têm grande importância, pois, além de fornecerem sombra para determinadas espécies, apresentam um papel ecológico muito importante no que diz respeito a conservação do solo, visto que suas copas podem diminuir o impacto das chuvas que provoca erosão e compactação do solo; e suas raízes, quando densas e profundas são capazes de evitar o arraste das partículas do solo, podendo também absorver os nutrientes nas camadas mais profundas do solo (MONTAGNINI, 1992; RODRIGUES et. al., 2007; MAFRA et al. 2008).

Além dessas funções produtivas, a serapilheira foliar desempenha importante papel na dinâmica desses ecossistemas, uma vez que ao ser decomposta torna-se uma grande fonte de nutrientes para as plantas, além de proteger o solo de ações erosivas (SHEER, 2008, PAULA et al., 2009, GIÁCOMO et al., 2012).

Isto posto, tem-se que as espécies selecionadas para compor o desenho de um SAF, devem simultaneamente cumprir o objetivo do plantio e as exigências ecológicas regionais, garantindo, assim, retornos econômicos e ambientais satisfatórios (MELOTTO et al., 2009). Outrossim, os 
SAFs podem apresentar desenhos ou arranjos simples, com poucas espécies por unidade de área, ou complexos, com grande diversidade de espécies, cujos benefícios nem sempre são fáceis de quantificar (PAULA et al., 2015). Diante do exposto, o presente estudo objetivou avaliar o crescimento inicial e sobrevivência de três espécies florestais de importância econômica e ecológica na Amazônia implantadas em SAF sob diferentes condições de preparo de área e manejo na Fazenda Experimental da Universidade Federal do Oeste do Pará (UFOPA).

A pesquisa foi conduzida na Fazenda Experimental da Universidade Federal do Oeste do Pará (UFOPA), com sede nas coordenadas $\mathrm{S}$ $02^{\circ} 41^{\prime} 16,1^{\prime \prime}$ e W 54031'56,0' situada no município de Santarém, Pará, à margem esquerda da Rodovia PA 370 - "Santarém/Curuá-Una", no km 37. A classificação climática da região é Am (classificação Köppen), sendo, quente e úmido, com variação de temperatura média anual na faixa de $25^{\circ} \mathrm{C}$ a $28^{\circ} \mathrm{C}$ e a umidade relativa média do ar de
86\%. A precipitação média anual é de 1920 mm, variando de 170 mm.mês ${ }^{-1}$ a 60 mm.mês ${ }^{-1}$ (FERREIRA, 2011).

Os solos são do tipo Latossolo Amarelo texturas médias, argilosas e muito argilosas em associações com os solos Concrecionários Lateríticos Indiscriminados distróficos textura indiscriminada (IDESP, 2014). Até a década de 1980, a área era utilizada para atividades voltadas para a pecuária, principalmente criação de animais bovinos e, posteriormente ficou em pousio por cerca de 10 anos antes da implantação do experimento deste estudo.

O experimento com o Sistema Agroflorestal Experimental foi instalado em março de 2016 e perfaz uma área útil de 1 ha. O sistema foi dividido em dois regimes de manejo: a) Mecanizado, onde foi utilizado implemento agrícola para remover a vegetação da área; b) Semimecanizado, utilizando apenas ferramentas manuais e semimecanizada (roçadeira costal) para depor a vegetação. A disposição dos 
mesmos em campo compreende dois blocos de cada regime, com quatro parcelas cada e dois tipos de arranjo de espécies distintos (Figura 1).

Figura 1. Esquema do desenho experimental do sistema agroflorestal experimental estudado, município de Santarém/PA.

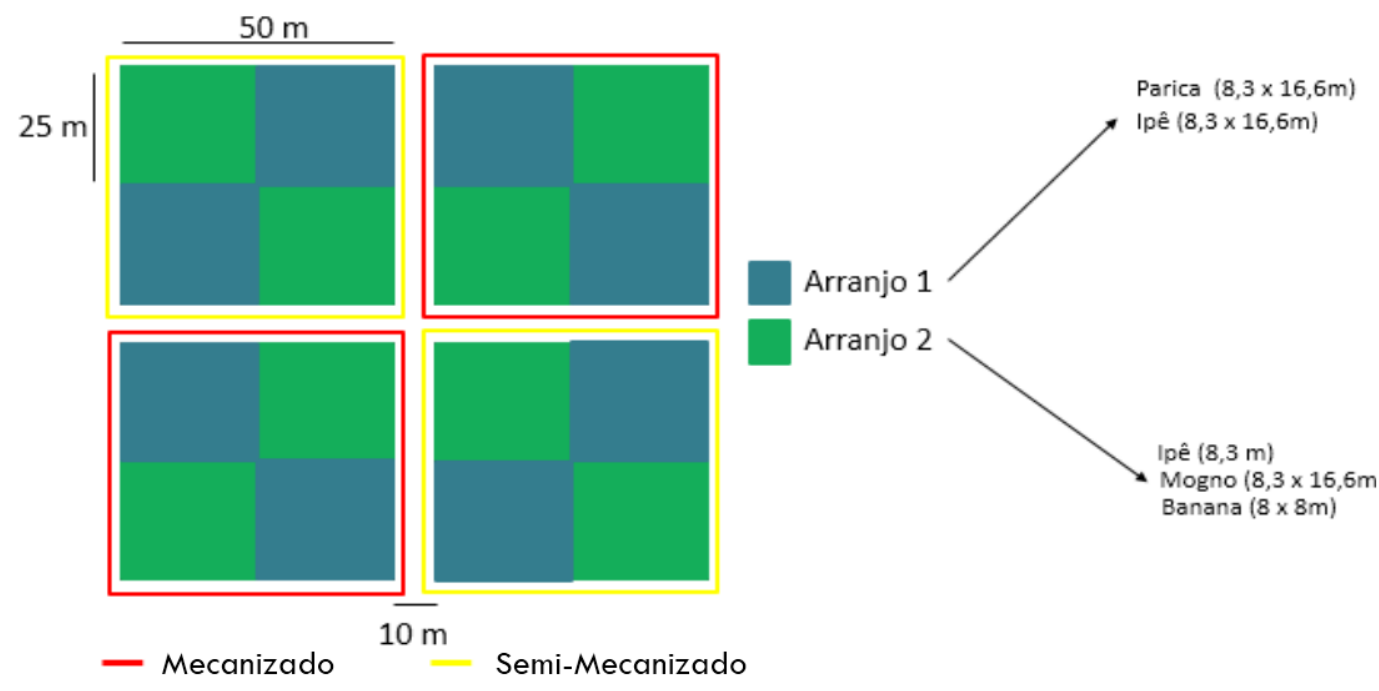

Fonte: Autor próprio.

O arranjo 1 é composto por lpê Amarelo (Handroanthus serratifolius (Vahl) S.O. Grose), Paricá ( Schizolobium parahyba var. amazonicum (Huber ex Ducke) Barneby). No segundo foram introduzidas o Mogno Brasileiro (, Ipê amarelo S.O. Grose), Banana (Musa sp.). Em ambos os arranjos houve também a introdução de espécies para adubação verde como Feijão de porco (Canavalia ensiformis (L.) DC.) e Crotalária (Crotalaria juncea L.).
Para o monitoramento do crescimento das espécies, os indivíduos foram enumerados através de placas de identificação e mensurados a partir do sétimo mês de implantação em campo. Realizou-se mensalmente a mensuração das variáveis altura total $(\mathrm{Ht})$ e diâmetro a altura do colo (DAC) utilizando trenas e paquímetro digital, respectivamente. Para as análises desse estudo, considerou-se o período correspondente a outubro de 2016 até 
julho de 2017. A partir das variáveis coletadas, calculou-se as Taxas de Crescimento Relativo (TCR) das espécies para os parâmetros Ht e DAC, por meio da fórmula expressa por Benincasa (2003):

$$
T C R=\left(\ln p_{2}-\ln p_{1}\right) /\left(T_{2}-T_{1}\right)
$$

Onde: $T C R=$ Taxa de crescimento relativo da variável avaliada $\left(\mathrm{cm}\right.$ por mês); $p_{1}$ e $p_{2}=$ variável acumulada nos tempos $T_{7}=7$ meses e $T_{2}=15$ meses.

Para avaliação do crescimento mensal em DAC em cada regime de manejo, submeteu-se as médias mensais ao teste $\mathrm{t}$ de Student nãopareado, ao nível de 95\% de probabilidade. Para a variável $\mathrm{Ht}$, utilizou-se o incremento total, também submetida ao teste supracitado. As análises foram realizadas através do software Bioestat.

A espécie H. serratifolius apresentou melhor desenvolvimento no bloco semi-mecanizado em todas as idades observadas diferente da espécie $S$. macrophylla que apresentou crescimento contínuo desde o período inicial nos dois blocos, com exceção do período entre 9 e 10 meses onde ocorre um comportamento estático de crescimento no bloco semimecanizado. Nota-se que, até 10 meses de idade a espécie apresenta melhor desempenho no bloco semimecanizado, a partir desse período, ocorre uma inversão no desenvolvimento da espécie onde ela passa a se sobressair no bloco mecanizado. Nota-se que S. parahyba apresenta melhores respostas em relação à altura total acumulada no bloco mecanizado, apesar de apresentar um ínfimo decréscimo no seu desenvolvimento aos 8 meses de idade nos dois blocos (Figura 2). 
Figura 2. Altura total acumulada Ipê amarelo (A); Mogno (B) e Paricá (C) em dois regimes de manejo de um sistema agroflorestal em Santarém, Pará.

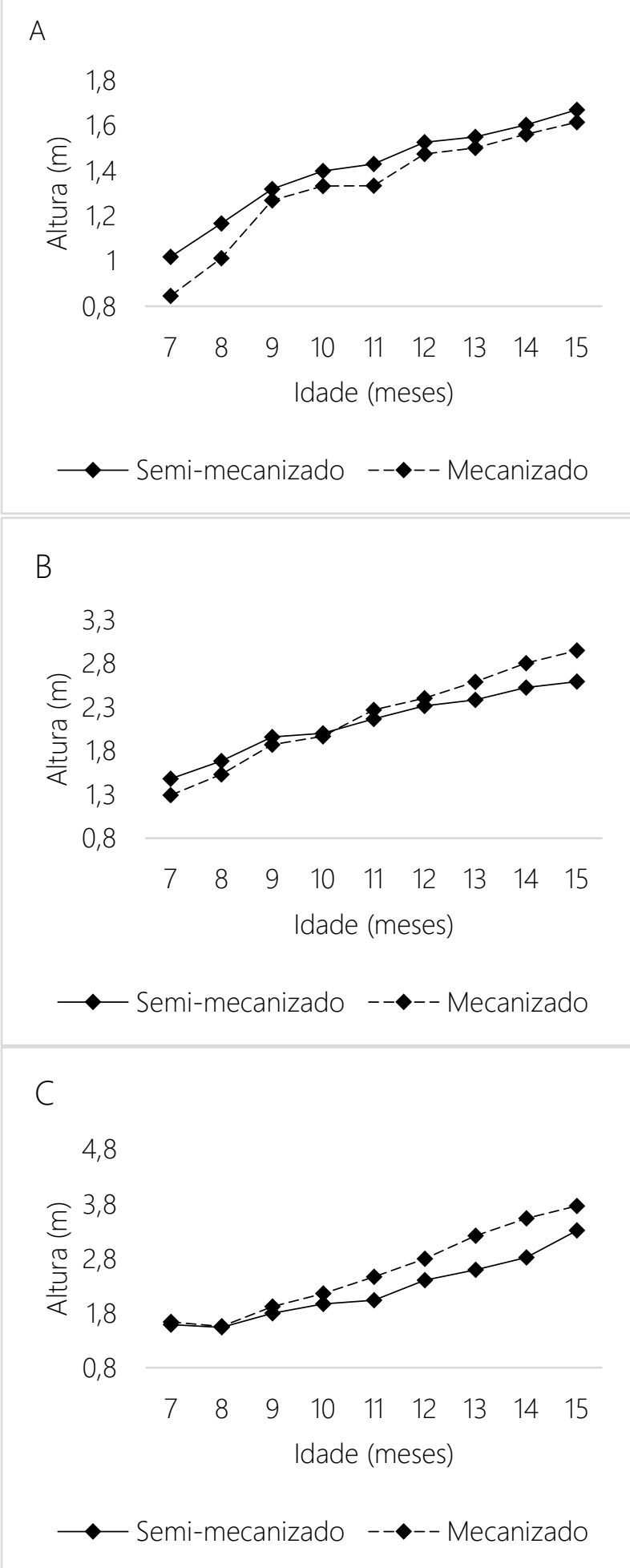

Fonte: Autor próprio. 
No que tange ao crescimento das espécies em diâmetro (cm), observouse que os melhores desempenhos se deram nos blocos mecanizados e em períodos de baixa precipitação (Figura 3) com valores de $7 \mathrm{~cm}, 6 \mathrm{~cm}$ e $2,5 \mathrm{~cm}$ para S. parahyba, S. macrophylla e $H$. serratifolius, respectivamente. Estes resultados diferem do que foi encontrado por Biz (2012) para $H$. serratifolius, 2,2 cm, aos sete meses de idade.

A taxa de sobrevivência das espécies pode ser observada na figura 4, onde H. serratifolius apresenta maiores taxas nos dois tratamentos, assemelhandose aos resultados encontrados por Melotto et al. (2009), tais resultados podem ser explicados pelo fato da espécie apresentar respostas positivas de sobrevivência quando implantada em solos de textura argilosa, Castro et al. (2011) baseiam-se nestes argumentos para explicar seus resultados ao estudar a espécie supracitada. Para do S. macrophylla e S. parahyba os resultados obtidos são semelhantes aos encontrados por Melo
(2000) e Gomes et al. (2010). S. macrophylla apresenta a menor taxa de sobrevivência no experimento, este fato pode ser explicado devido ao ataque da mariposa Hypsipyla grandella Zell, que ataca as plantações da região, esta danifica o mesristema apical da espécie, consequentemente, gerando danos ao seu desenvolvimento.

Porém, Costa et al. (2013) ao estudarem a espécie não identificaram a atuação da praga na fase inicial dos indivíduos analisados. A elevada taxa de sobrevivência do S. parahyba se explica pelo fato de que esta é uma espécie responde positivamente quando submetida a condições extremas, sobretudo, na região amazônica que passa por períodos de seca intensa em determinados períodos do ano.

Na Tabela 1 estão contidas as médias mensais da variável DAC por espécie, nos dois tratamentos do sistema. Pode-se notar que os diferentes regimes de manejo e preparo da área não causaram efeitos 
no crescimento em diâmetro para o lpê Amarelo, como demostrado pelo teste

t. Para a espécie Paricá, constatou-se diferença estatística significativa nos diâmetros médios entre os regimes de manejo nas idades de 11 e 13 meses.

Figura 3. Diâmetro a altura do colo acumulado Ipê amarelo (A); Mogno (B) e Paricá (C) em dois regimes de manejo de um sistema agroflorestal em Santarém, Pará.

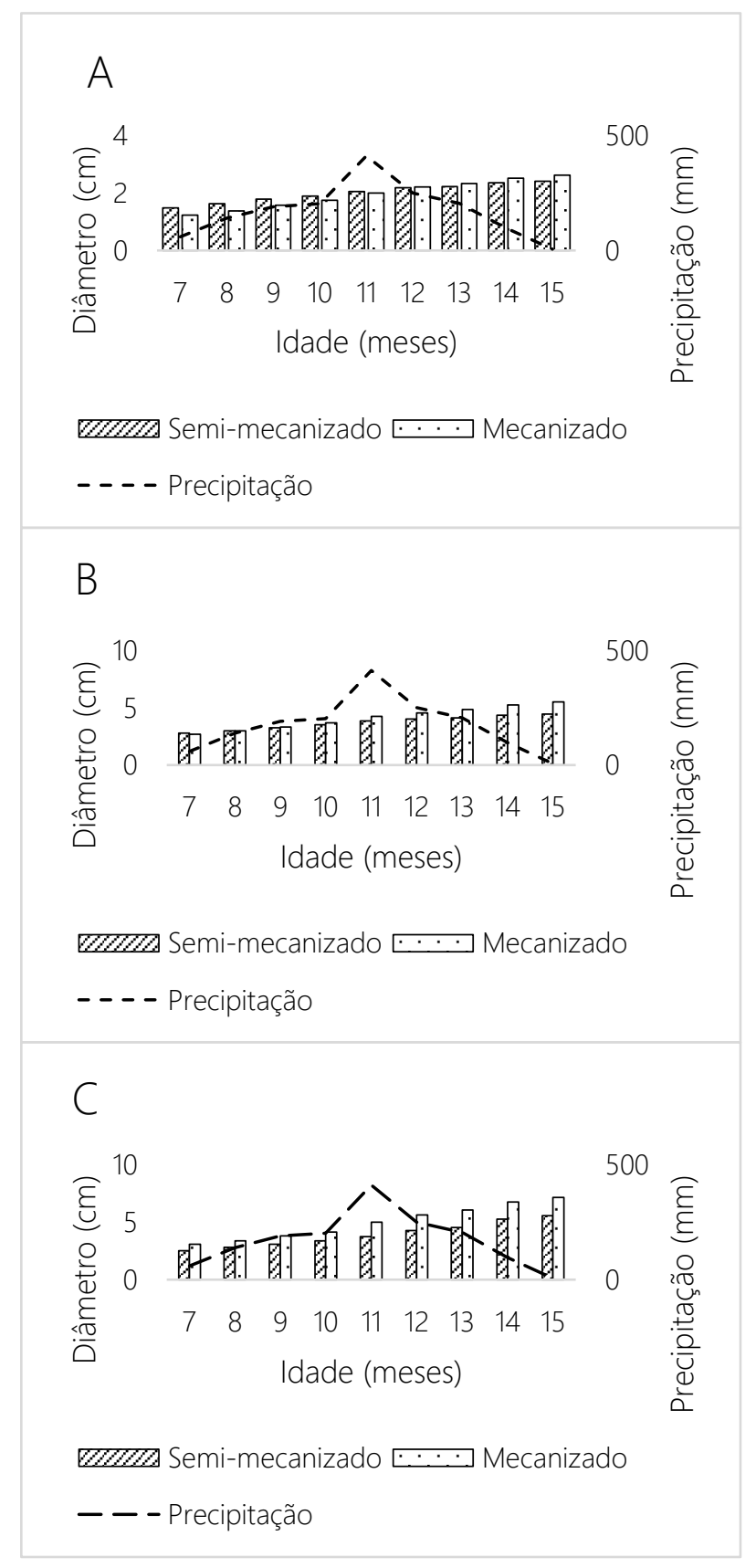

Fonte: Autor próprio. 
Figura 4. Taxa de sobrevivência de espécies florestais em dois regimes de manejo de um sistema agroflorestal em Santarém, Pará.

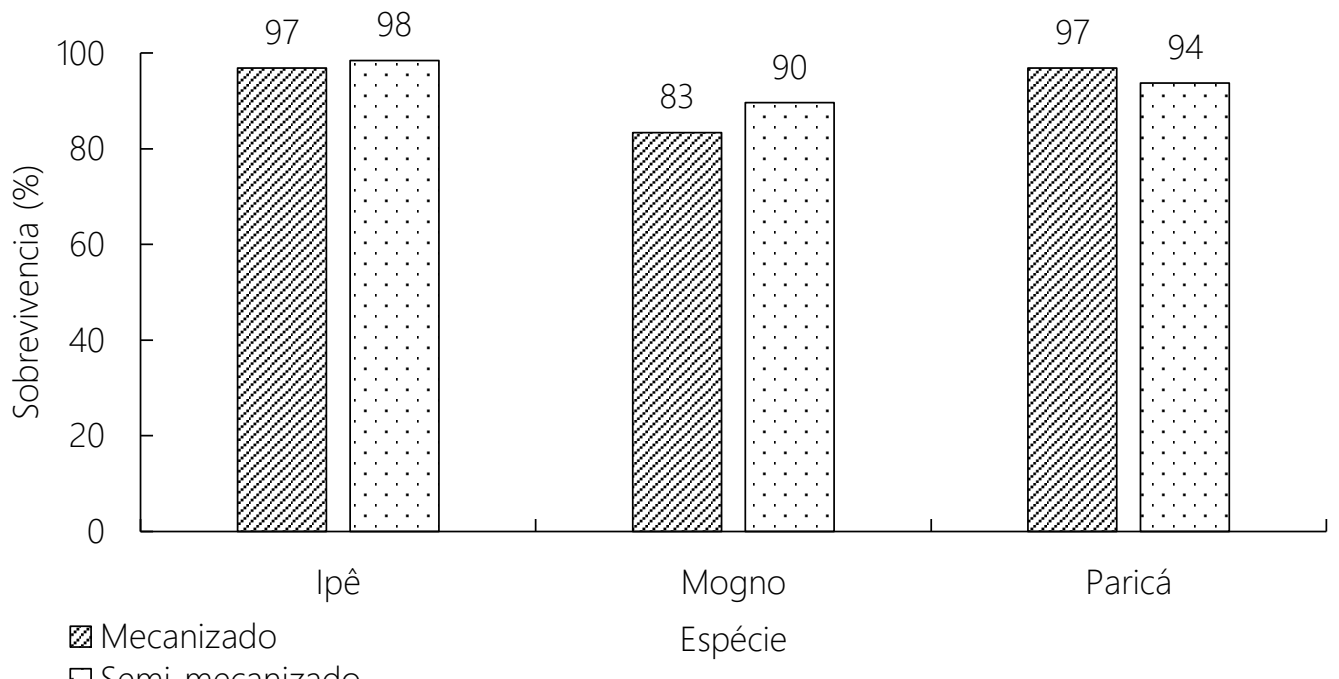

Fonte: Autor próprio.

Verificou-se também, que a partir da idade de 14 meses, os regimes começaram a influenciar o crescimento em DAC para o Mogno, com diferença significativa nas médias a partir dessa idade. A partir do $13^{\circ}$ mês de idade, o tratamento mecanizado apresentou as maiores médias em DAC para ambas as espécies.

Quanto ao incremento médio em altura total (Tabela 2), apenas o Mogno respondeu aos diferentes tratamentos de manejo, com incremento médio em altura superior nos blocos mecanizados. O Paricá foi a espécie com os maiores incrementos em altura e o Ipê Amarelo, a que menos se destacou neste parâmetro.

Estão contidas na Tabela 3 as taxas médias de crescimento relativo para as espécies avaliadas onde nota-se que somente a espécie Paricá não demonstrou diferença estatística significativa nas taxas de crescimento. O Paricá também foi a espécie que apresentou o maior crescimento relativo, para ambas as variáveis. 
Tabela 1. Diâmetro a altura do colo (cm) médio das espécies avaliadas nos dois regimes de manejo por mês em sistema agroflorestal em Santarém, Pará.

\begin{tabular}{|c|c|c|c|c|c|}
\hline \multirow{2}{*}{ Espécie } & \multirow{2}{*}{$\begin{array}{c}\text { Idade } \\
\text { (meses) }\end{array}$} & \multicolumn{2}{|c|}{ Diâmetro à altura do colo $(\mathrm{cm})$} & \multicolumn{2}{|c|}{ Teste $t$} \\
\hline & & Semi-mecanizado & Mecanizado & $t_{\text {cal }}$ & valor-p \\
\hline \multirow{9}{*}{ Ipê } & 7 & 1,64 & 1,29 & 1,5466 & 0,1442 \\
\hline & 8 & 1,80 & 1,45 & 1,3131 & 0,2102 \\
\hline & 9 & 1,95 & 1,64 & 1,1671 & 0,2626 \\
\hline & 10 & 2,07 & 1,84 & 0,8294 & 0,4208 \\
\hline & 11 & 2,27 & 2,11 & 0,4416 & 0,6655 \\
\hline & 12 & 2,41 & 2,35 & 0,1669 & 0,8699 \\
\hline & 13 & 2,44 & 2,47 & 0,0800 & 0,9373 \\
\hline & 14 & 2,59 & 2,63 & 0,0827 & 0,9353 \\
\hline & 15 & 2,64 & 2,77 & 0,3074 & 0,7631 \\
\hline \multirow{9}{*}{ Mogno } & 7 & 2,77 & 2,59 & 0,7984 & 0,4550 \\
\hline & 8 & 2,97 & 2,88 & 0,3233 & 0,7575 \\
\hline & 9 & 3,22 & 3,24 & 0,0643 & 0,9508 \\
\hline & 10 & 3,51 & 3,60 & 0,3731 & 0,7219 \\
\hline & 11 & 3,83 & 4,18 & 1,4366 & 0,2008 \\
\hline & 12 & 3,98 & 4,47 & 1,7637 & 0,1282 \\
\hline & 13 & 4,09 & 4,75 & 2,2038 & 0,0697 \\
\hline & 14 & 4,33 & 5,16 & 2,9059 & 0,0271 \\
\hline & 15 & 4,42 & 5,42 & 3,4633 & 0,0134 \\
\hline \multirow{9}{*}{ Paricá } & 7 & 2,53 & 3,08 & 2,0475 & 0,0865 \\
\hline & 8 & 2,80 & 3,38 & 2,0142 & 0,0906 \\
\hline & 9 & 3,08 & 3,81 & 2,4468 & 0,0499 \\
\hline & 10 & 3,38 & 4,16 & 1,8738 & 0,11 \\
\hline & 11 & 3,74 & 5,00 & 2,6449 & 0,0382 \\
\hline & 12 & 4,28 & 5,64 & 2,1712 & 0,0729 \\
\hline & 13 & 4,54 & 6,08 & 2,4499 & 0,0497 \\
\hline & 14 & 5,28 & 6,77 & 1,8841 & 0,1085 \\
\hline & 15 & 5,56 & 7,20 & 2,156 & 0,0744 \\
\hline
\end{tabular}

Tabela 2. Incrementos médios em altura total $(\mathrm{m})$ por idade para as espécies florestais avaliadas nos dois regimes de manejo por mês em sistema agroflorestal em Santarém, Pará.

\begin{tabular}{ccccc}
\hline Espécie & Semi-mecanizado & Mecanizado & $t_{\text {cal }}$ & valor- $p$ \\
\hline Ipê amarelo & 0,69 & 0,80 & 0,7248 & 0,4805 \\
Mogno & 1,13 & 1,62 & 2,9042 & 0,0271 \\
Paricá & 1,72 & 2,16 & 0,9552 & 0,3763 \\
\hline
\end{tabular}


Tabela 3. Taxa de crescimento relativo em diâmetro a altura do colo e altura total para as espécies florestais avaliadas nos dois regimes de manejo em sistema agroflorestal em Santarém, Pará.

\begin{tabular}{lllll}
\hline TCR $\left(\mathrm{cm}^{*} \mathrm{~cm}^{-1} / \mathrm{mês}\right)$ & Espécie & Semi-mecanizado & Mecanizado & valor-p \\
\hline \multirow{4}{*}{ Diâmetro } & Ipê Amarelo & 0,06 & 0,09 & 0,013 \\
& Mogno & 0,06 & 0,09 & 0,006 \\
& Paricá & 0,10 & 0,11 & 0,248 \\
\hline \multirow{3}{*}{ Altura total } & Ipê Amarelo & 0,069 & 0,071 & 0,035 \\
& Mogno & 0,095 & 0,120 & 0,034 \\
& Paricá & 0,012 & 0,014 & 0,426 \\
\hline
\end{tabular}

As espécies apresentam índices de crescimento inicial e sobrevivência satisfatórios, e, consequentemente podem ser indicadas para plantio sistemas agroflorestais.

O paricá apresenta características desejáveis para implantação de sistemas agroflorestais sobretudo para a recuperação de áreas degradadas.

Os estudos sobre tal temática devem ser aprofundados para que se tenha melhor conhecimento sobre o desempenho das espécies nas localidades onde se encontram.

\section{REFERÊNCIAS}

ABDO, M. T. V. N.; VALERI, S. V.; MARTINS, A. L. M. Sistemas agroflorestais e agricultura familiar: uma parceria interessante. Revista Tecnologia \& Inovação Agropecuária, v. 1, n. 2. 2008.

BIZ, S.; BRITO, N.M.; REGO, G.M.S.; $B R U N$, E.J. Crescimento inicial em diâmetro de colo de espécies florestais nativas madeireiras plantadas em Dois Vizinhos - PR. In: IV CONGRESSO FLORESTAL PARANAENSE, 4, 2012, Curitiba, Anais... Curitiba, 2012, p.1-9

CASTRO, A. A.; MANESCHY, R. Q.; OLIVEIRA, I. K. S.; GUIMARÃES, T. P.; COSTA, K. C. G. Sobrevivência de espécies madeiráveis em sistema agrossilvipastoril em são domingos do Araguaia, $\mathrm{Pa}$.

Revista

Agroecossistemas, v. 3, n. 1, p. 111-115, 2011.

COSTA, M. S.; FEITOSA, C. T. L.; CRUZ, S. S.; RIBEIRO, S. B.; MORAIS, A. B. F.; OLIVEIRA, M. G. Crescimento do Mogno em sistema silvipastoril. Revista Agroecossistemas, v. 5, n. 2, p. 53-57, 2013. 
FERREIRA, J. D. Análise do plano processo na urbanização de cidades no Baixo Amazonas: o caso de Santarém - Brasil. 2011. 118 f. Dissertação (Mestrado em Desenvolvimento e Meio Ambiente Urbano). Universidade da Amazônia, Belém, 2011.

GIÁCOMO, R. G.; PEREIRA, M. G. \& MACHADO, D. L. Aporte e decomposição de serapilheira em áreas de Cerradão e Mata Mesofítica na Estação Ecológica de Pirapitinga MG. Ciência Florestal, v.22, n.4, p.669680. 2012.

GOMES, J. M.; CARVALHO, J. O. P.; SILVA, M. G.; NOBRE, D. N. V.; TAFFAREL M.; FERREIRA, J. E. R.; SANTOS, R. N. J. Sobrevivência de espécies arbóreas plantadas em clareiras causadas pela colheita de madeira em uma floresta de terra firme no município de Paragominas na Amazônia brasileira, Acta Amazônica, v. 40, n. 1, p. $171-178,2010$.

IDESP. Estatísticas Municipal de Santarém. 2014 www.idesppa.gov.br/pdf/statisticaMuni cipal). Acesso em: 14/03/2015.

LIMA, S. S.; LEITE, L. F. C.; AQUINO, A. M.; OLIVEIRA, F. C.; Castro, A. A. J. F. Estoques da serrapilheira acumulada e teores de nutrientes em Argissolo sob manejo agroflorestal no norte do Piauí. Revista Árvore, v.34, n.1, p.75-84, 2010.

MARTINOTTO, F.; MARTINOTTO C; COELHO, M. F. B.; AZEVEDO, R. A. B.; ALBUQUERQUE, M. C. F. Sobrevivência e crescimento inicial de espécies arbóreas nativas do Cerrado em consórcio com mandioca. Pesquisa Agropecuária Brasileira, Brasília, v.47, n.1, p.22-29, jan. 2012.

MAFRA, A. L., GUEDES, S. F. F., KLAUBERG FILHO, O., SANTOS, J. C. P., ALMEIDA, J. A. \& ROSA, J. D. Carbono orgânico e atributos químicos do solo em áreas florestais. Revista Árvore, v.32. n.2, p.217-224. 2008.

MELO, J. T. D., GUIMARÃES, D. P. A cultura do café em sistemas consorciados na região do Cerrado. In: SIMPÓSIO DE PESQUISA DOS CAFÉS DO BRASIL, Poços de Caldas, 2000.Anais... Poços de Caldas: Embrapa Café, 2000. p. 26-29.

MELOTTO, A.; NICODEMO, M. L.; BOCCHESE, R. A.; LAURA, V. A.; GONTIJO NETO, M. M.; SCHLEDER, D. D.; POTT, A.; SILVA, V. P. Sobrevivência e crescimento inicial em campo de espécies Florestais nativas do brasil central indicadas para sistemas Silvipastoris. Revista Árvore, ViçosaMG, v.33, n.3, p.425-432, 2009

MONTAGNINI, F. Sistemas agroflorestais: princípios y aplicaciones em los trópicos. 2. Ed. Ver. Aum. San José: Organización para Estúdios Tropicales, 1992. 622 p.

PAULA, R. R., PEREIRA, M. G. \& MENEZES, L. F. T. Aporte de nutrientes e decomposição da serapilheira em três fragmentos florestais periodicamente inundados na Ilha da 
Marambaia, RJ. Ciência Florestal, v.19, n.2, p.139-148. 2009.

PAULA, P. D.; CAMPELLO, E. F.; GUERRA, J. G. M.; SANTOS, G. A.; RESENDE, A. S. Decomposição das podas das leguminosas arbóreas Gliricidia sepium e Acacia angustissima em um sistema agroflorestal. Ciência Florestal, Santa Maria, v. 25, n. 3, p. 791800, jul.-set., 2015.

RODRIGUES, E. R.; CULLEN, L.; BELTRAME, T. P.; MOSCOGLIATO, A.V.; SILVA, I.C. Avaliação econômica de sistemas agroflorestais implantados para recuperação de reserva legal no pontal do Paranapanema, São Paulo. Revista Árvore, Viçosa-MG, v.31, n.5, p.941-948, 2007.

RODRIGUES, E. R.; CULLEN, L.; BELTRAME, T. P.; MOSCOGLIATO, A.V.; SILVA, I.C. O uso do sistema agroflorestal taungya na restauração de reservas legais: indicadores econômicos. Floresta, Curitiba, PR, v. 38, n. 3, jul./set. 2008.

SCHEER, M. B. Decomposição e Liberação de Nutrientes da Serapilheira Foliar em um Trecho de Floresta Ombrófila Densa Aluvial em Regeneração, Guaraqueçaba (PR). Floresta, v.38, n.2, p.253-266. 2008.

VALERI, S. V.; POLITANO, W.; SENO, K. C. A.; BARRETO, A. L. N. M. Sistemas agroflorestais: Manejo e recuperação Florestal. Jaboticabal: Funep, 2003. 180 p. 